\title{
Desbridamiento apropiado y técnica de "pie-crusting" en el manejo de la herida traumática
}

\author{
Luis A. Beraún Coronel," Manuel O. Becerra Orrego,"* José G. Quispe Juárez** \\ "Servicio de Ortopedia y Traumatología, Hospital II-2 Tarapoto, Tarapoto, Perú \\ ${ }^{* *}$ Servicio de Ortopedia y Traumatología, Hospital Nacional Dos de Mayo, Lima, Perú
}

\begin{abstract}
RESUMEN
Las heridas crónicas de origen traumático, con exposición de tejidos, requieren de un desbridamiento adecuado, lavado y una pronta cubierta para evitar la infección y la desecación. A veces, incluso deben ser ampliadas para realizar un adecuado desbridamiento quirúrgico; por lo que, al intentar una cobertura completa, el resultado es una herida a tensión, que se complica con inflamación, infección y la dehiscencia que se acentúa aún más si está en una zona de flexión, como la rodilla. Se presenta el caso de una paciente de 28 años, que acudió a emergencias con un antecedente de herida traumática en la rodilla derecha, signos de retraso de la cicatrización, tejido de granulación friable, exposición de la rótula, abundante secreción serosa y dolor al movimiento con rango limitado. Se la trató en un solo tiempo quirúrgico con desbridamiento, irrigación y cobertura completa de la herida mediante la técnica de "pie-crusting".
\end{abstract}

Palabras clave: "Pie-crusting"; herida ulcerativa traumática; incisiones cutáneas; desbridamiento; cierre de la herida.

Nivel de Evidencia: IV

Adequate debridement and pie-crusting technique in the management of traumatic injuries

\section{ABSTRACT}

Chronic wounds of traumatic origin, with tissue exposure, require adequate debridement, lavage and prompt coverage to prevent infection and desiccation. Wounds may even require to be enlarged in order to perform an adequate surgical debridement. Enlarged wound attempts to perform a complete coverage may result in tension wound closures, which are complicated by inflammation, infection, and dehiscence and aggravated when located on flexure areas, such as on the knee. We report the case of a 28-year female patient, who presented to the Emergency Department with a history of traumatic wound in the right knee and signs of delayed healing, friable granulation tissue, exposed patella, increased serous drainage, and painful limited range of motion. She underwent a single surgical time procedure with debridement, irrigation, and complete coverage of the wound with the help of the pie-crusting technique.

Key words: Pie-crusting; ulcerative traumatic wound; skin incisions; debridement; wound closure.

Level of Evidence: IV

\section{INTRODUCCIÓN}

El tratamiento de las heridas traumáticas requiere una limpieza profunda y un cierre libre de tensión para lograr un proceso de curación adecuado; un mal manejo puede llevar a la ulceración y a la exposición del tejido óseo y miotendinoso, dificultando el tratamiento y limitando las actividades del paciente. ${ }^{1}$ El primer paso para el tratamiento de una herida ulcerada de causa traumática es el desbridamiento ${ }^{2,3}$ de todo el tejido no viable, sumado a la ampliación de la herida para una adecuada exploración. Luego se lava con solución salina normal y agentes antisépticos o sin ellos, ${ }^{4,5}$ que permitirán generar un medio de curación favorable. Una vez concluido el procedimiento, se evalúa la posibilidad de nuevas limpiezas quirúrgicas o de cubrir el defecto en un primer tiempo quirúrgico, ya que se recomienda una pronta cobertura para evitar el secado y la infección de los tejidos expuestos. ${ }^{1}$ Para estos

Recibido el 23-5-2019. Aceptado luego de la evaluación el 30-7-2019 • Dr. LUIS Á. BERAÚN CORONEL • langel_15@hotmail.com

Cómo citar este artículo: Beraún Coronel LA, Becerra Orrego MO, Quispe Juárez JG. Desbridamiento apropiado y técnica de "pie-crusting" en el manejo de la herida traumática. Rev Asoc Argent Ortop Traumatol 2020;85(3):254-261. https://doi.org/10.15417/issn.1852-7434.2020.85.3.992 
casos, se emplean técnicas, como el uso de colgajos e injertos que requieren un tiempo hasta su incorporación completa. ${ }^{3}$ Sin embargo, existe la técnica de "pie-crusting", ${ }^{6-9}$ que ha sido descrita en estudios, aunque con muy poca difusión. Consiste en realizar múltiples incisiones, de 3-5 mm de largo, con bisturí $\mathrm{N}^{\circ} 15$, a través de la dermis, paralelas al borde de la herida y perpendiculares a las líneas de tensión, con una distancia de 5-10 mm entre incisiones, y en la cantidad necesaria para que la tensión en la herida esté abolida. Es simple y útil, ya que reduce la tensión y permite la expansión de la piel, disminuye el área de tejido expuesto e incluso se logra una cobertura completa. ${ }^{6,7}$ Posteriormente, se cubre con apósitos no adherentes y se protege con una férula para evitar el movimiento y la distensión de la herida.

\section{CASO CLÍNICO}

Mujer de 28 años que sufrió un accidente de tránsito como pasajera en motocicleta. Refiere que, al caer, su rodilla derecha impacta directamente contra el pavimento, lo que le produjo una herida profunda con exposición ósea (Figuras 1-3). Fue tratada en un hospital, donde se le realizó una limpieza tópica y un cierre de la herida. Continuó con curaciones tópicas cada dos días y la herida progresivamente se ulceró.

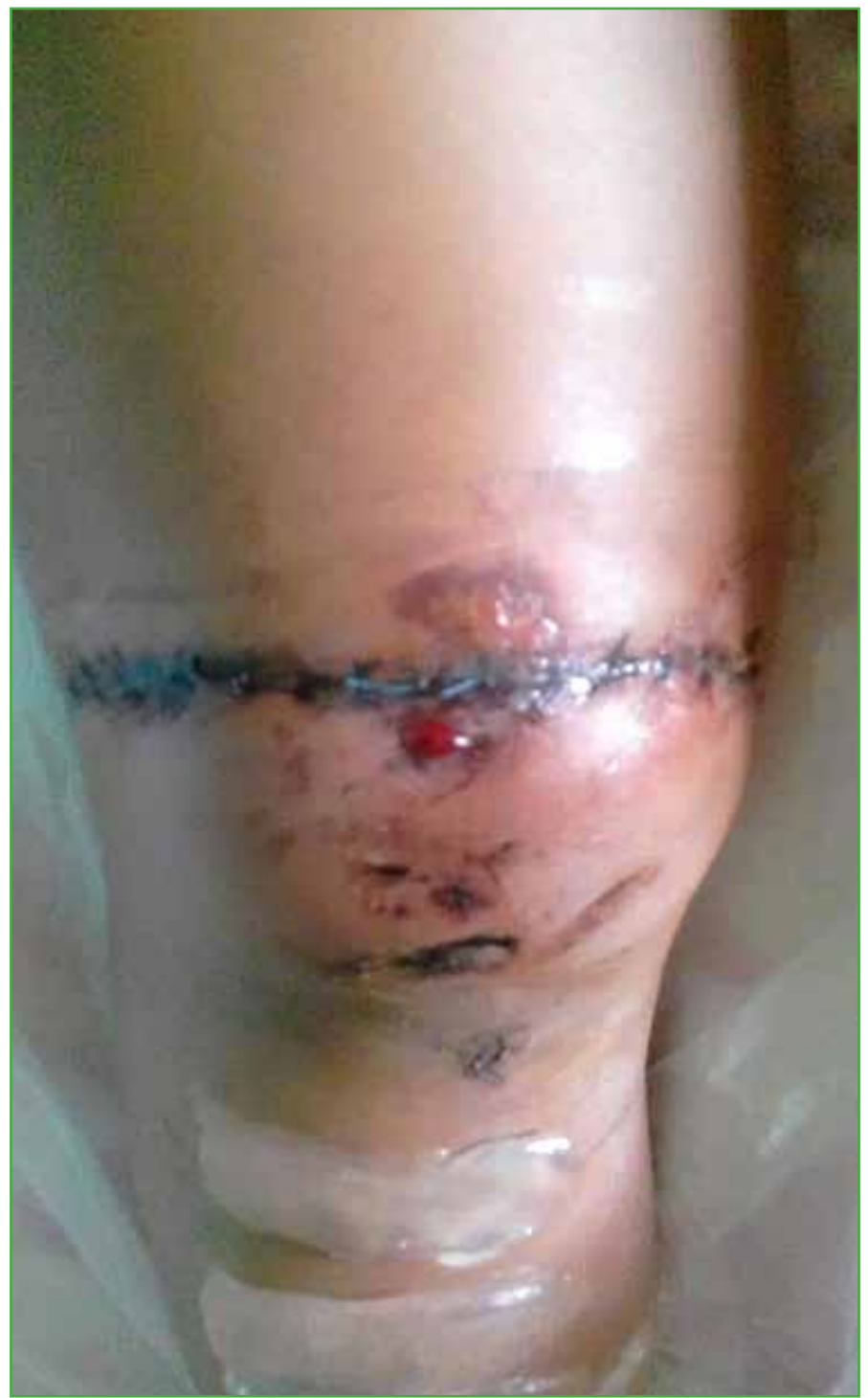

Figura 1. Evolución de la herida hacia la ulceración. Se observan tensión y flogosis. La paciente se coloca emplastos caseros. 


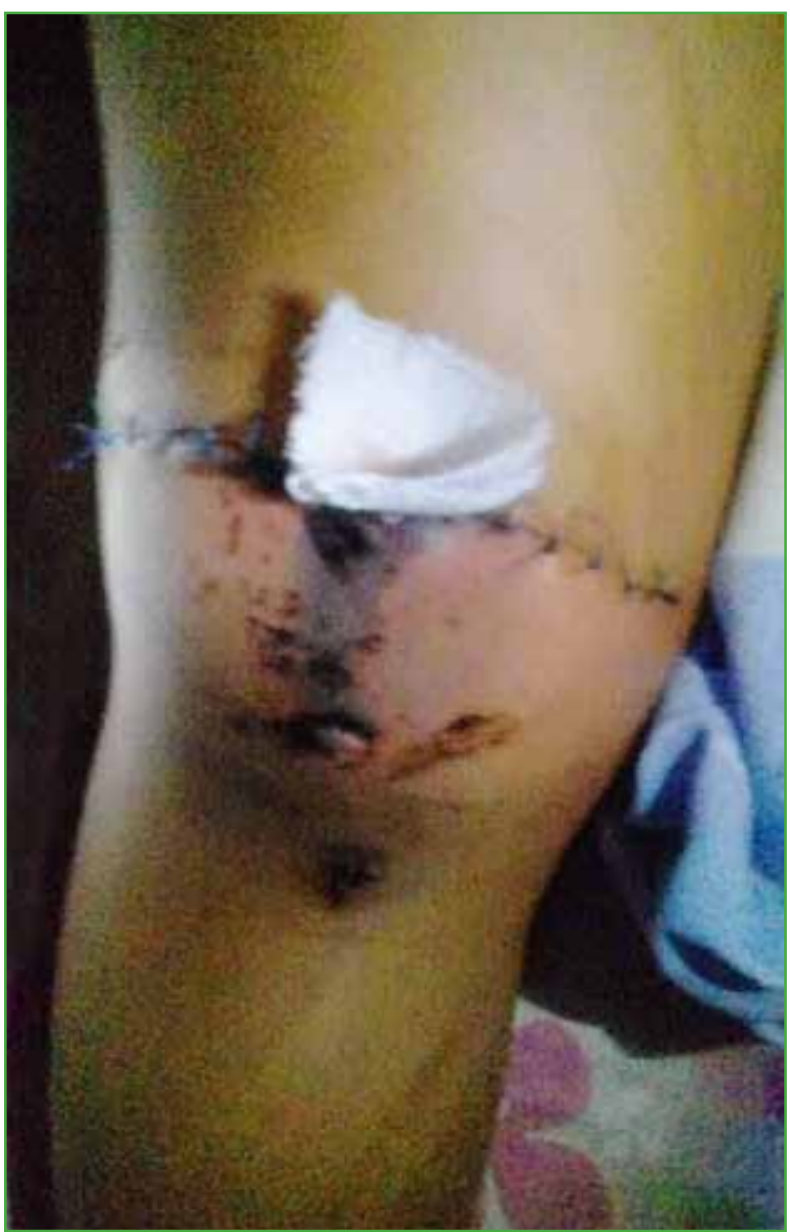

Figura 2. Se observan signos de necrosis con el transcurrir de los días, y disminución de la flogosis.

Figura 3. La paciente acude al hospital ya con ulceración de la herida, tejido de granulación friable, abundante secreción serosa y exposición de la rótula.

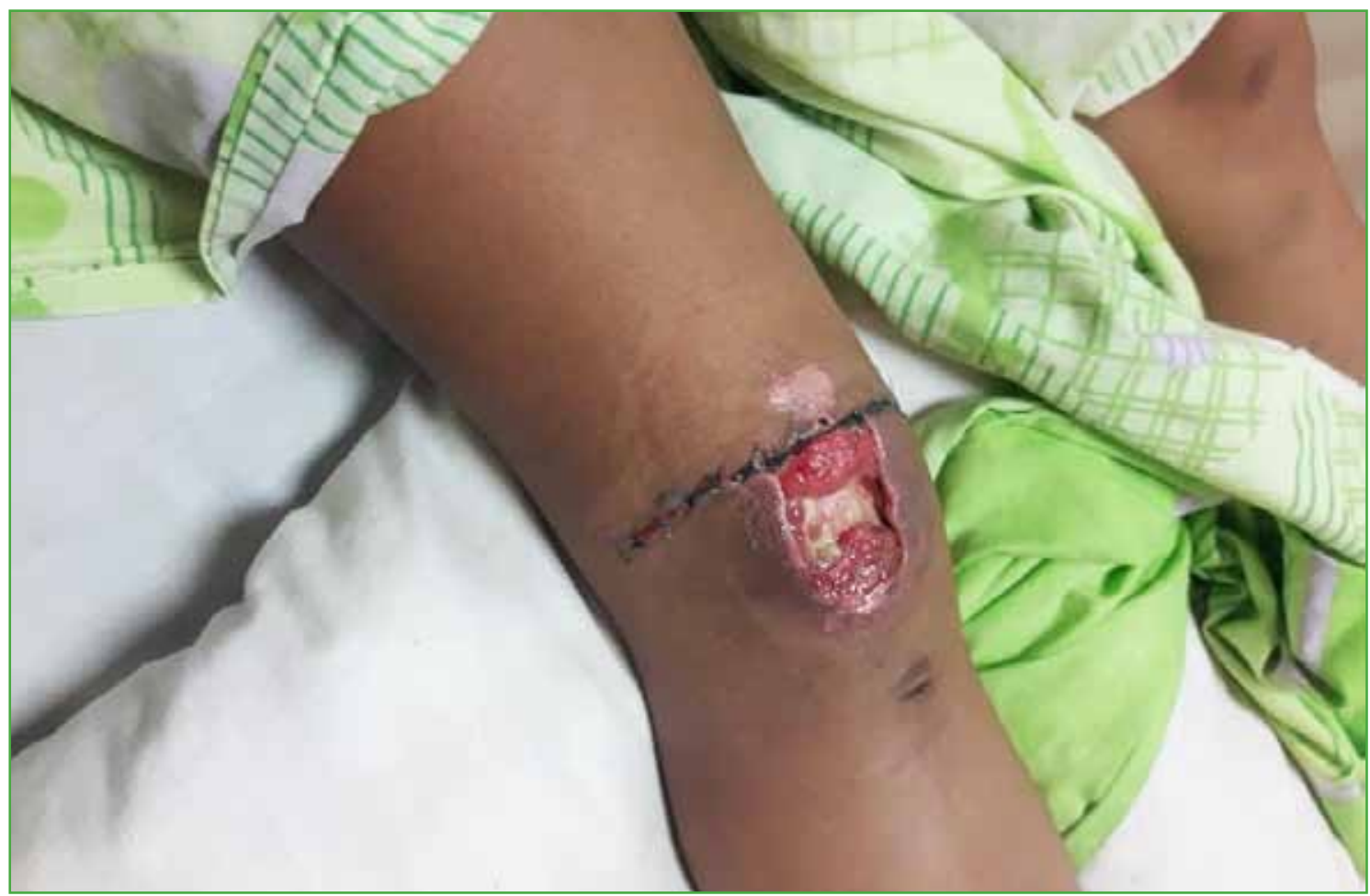


Después de cuatro semanas, acudió al Servicio de Urgencia del Hospital de Tarapoto por dolor de moderado a intenso en la herida de la rodilla. El examen físico reveló que no tenía fiebre, sus funciones vitales eran estables y tenía signos de desnutrición. Se observó una herida transversal en la rodilla derecha, suturada, de $20 \mathrm{~cm}$ de longitud, con ulceración en el tercio central, de $7 \mathrm{~cm}$ de ancho y $8 \mathrm{~cm}$ de largo, con bordes desvitalizados, abundante secreción serosa, tejido de granulación friable y necrótico, y también la exposición de la superficie anterior de la rótula, que estaba desecada. Sufría dolor moderado en la rodilla, que se acentuaba durante la flexión, lo que limitaba la deambulación. En las radiografías, no se visualizaron signos de compromiso articular.

Se realizó un desbridamiento quirúrgico del tejido desvitalizado, se limpió la superficie ósea expuesta, se resecaron los bordes hasta que hubo sangrado y se amplió la herida para una mejor evaluación, así fue posible detectar partículas de polvo adheridas en el retináculo rotuliano lateral y medial. El desbridamiento mecánico se realizó con $10 \mathrm{cc}$ de yodo povidona al 10\% más $10 \mathrm{cc}$ de peróxido de hidrógeno en $1000 \mathrm{cc}$ de solución salina normal, y luego con 91 de solución salina normal.

Tras una nueva evaluación, se decidió la cobertura de la rótula. En un primer momento, se cubrió solo un tercio de la superficie, de modo que se procedió con la técnica de "pie-crusting" practicando pequeñas incisiones de 0,5 a $1 \mathrm{~cm}$ de longitud, paralelas a la herida y otras perpendiculares a las líneas de tensión, y síntesis con puntos de sutura simples y de Blair-Donati; de esta manera, se logró, con poca tensión, la cobertura completa de la herida; se cubrió con gasa parafinada y se protegió con una férula muslopedia durante 14 días.

Se curó la herida al cuarto día (Figura 4), se observó escasa secreción serosa y ausencia de flogosis.

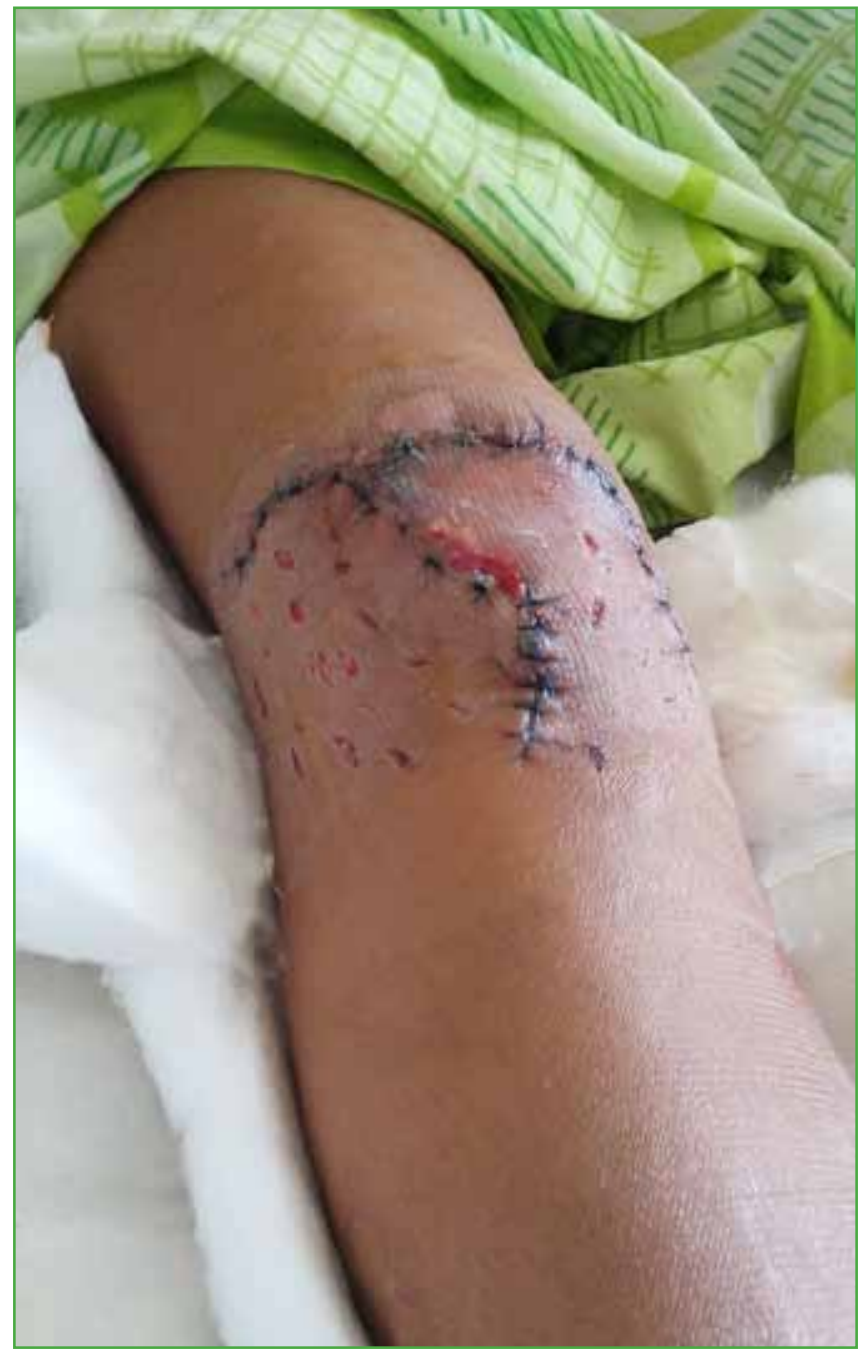

Figura 4. Evolución posoperatoria, control al cuarto día. Escasa secreción serohemática. 
Al sexto día (Figura 5), se detectó necrosis de la punta del colgajo de aproximadamente $2 \mathrm{~cm}$ x $2 \mathrm{~cm}$, se continuó con curaciones tópicas con solución salina; el área necrótica fue desbridándose mostrando signos de granulación.

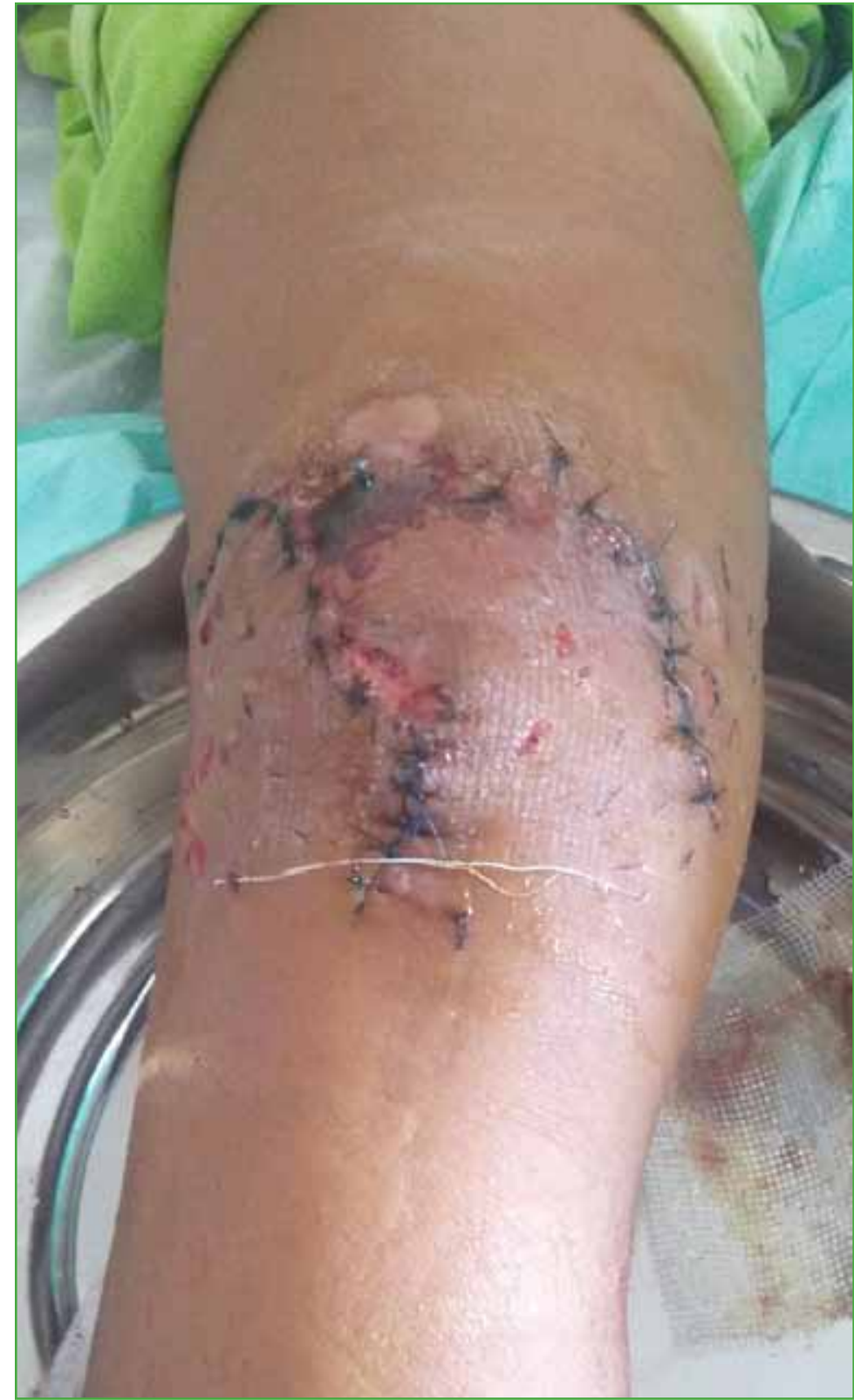

Figura 5. Evolución posoperatoria, control al sexto día. Necrosis de la punta del colgajo.

La paciente fue evaluada por un cirujano plástico quien le propuso un injerto de piel, pero rechazó nuevos procedimientos quirúrgicos y, ante una aparente buena evolución, continúa con las curaciones tópicas con Prontosan ${ }^{\circledR}$ solución y en gel. 
Al décimo día de la operación, es dada de alta, con antibióticos durante seis semanas. Después de dos semanas, se retiró la férula y, al mes, las incisiones del "pie-crusting” habían cicatrizado completamente (Figura 6).

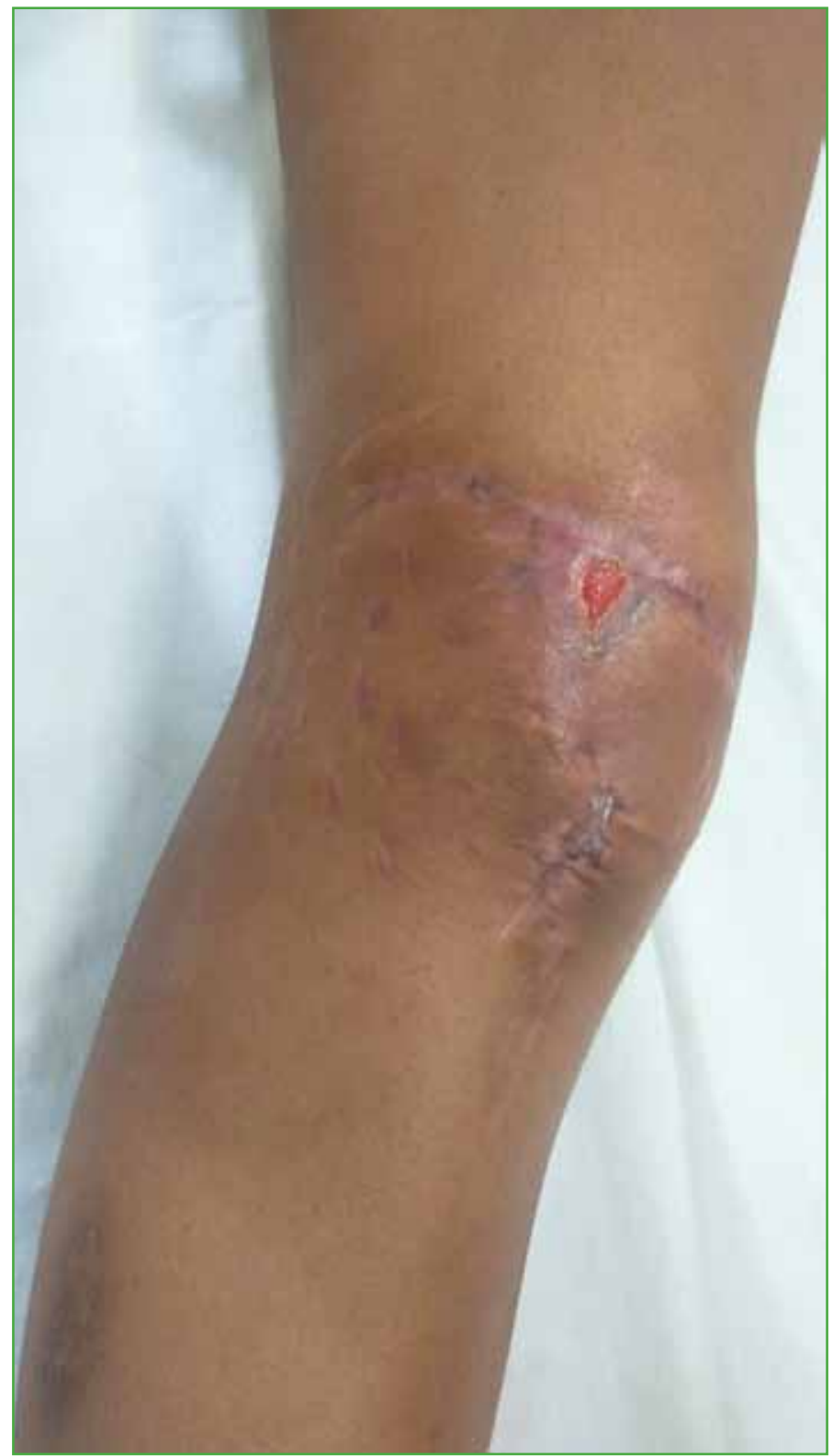

Figura 6. Evolución posoperatoria, control al mes. Zona con signos de granulación.

A la séptima semana, la herida había cerrado por completo, la paciente tenía poco dolor, un rango completo de flexión y extensión, un puntaje en la escala analógica visual de 2 (Figuras 7 y 8), no tenía signos de inestabilidad y caminaba sin dificultades. Se informó un ligero aumento de volumen en algunas oportunidades.

En la actualidad, a los nueve meses de evolución, el rango articular es completo y no hay signos de infección recurrente. 


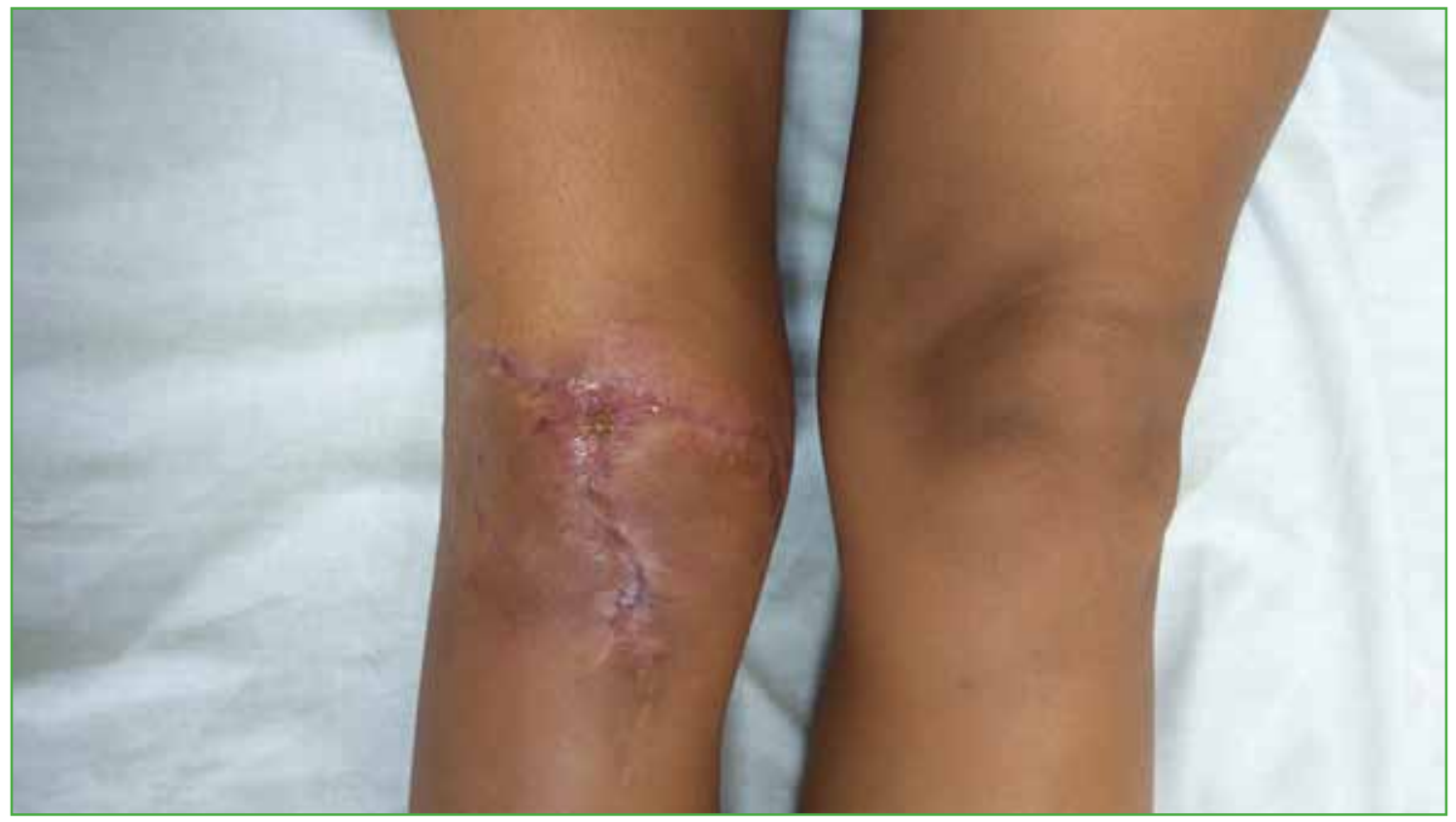

Figura 7. Evolución posoperatoria, control a las 7 semanas. Cierre completo de la herida.

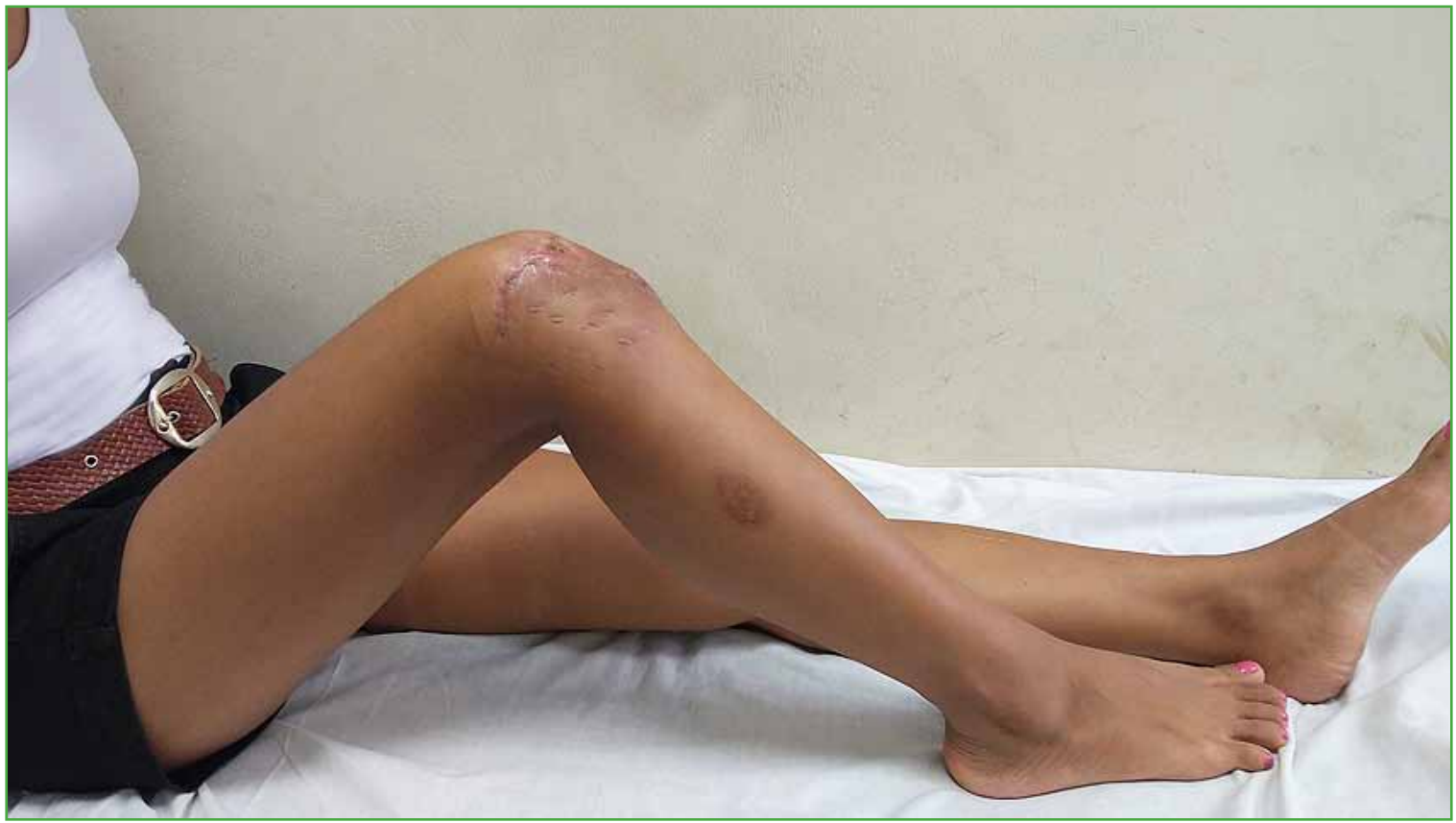

Figura 8. Evolución posoperatoria. La paciente deambula, con escaso dolor y flexión recuperada. 


\section{DISCUSIÓN}

En el manejo de heridas ulceradas con antecedentes traumáticos, es importante un adecuado desbridamiento. En este paso, existen controversias sobre el uso de una solución normal en el lavado o el uso de agentes antisépticos, que son bactericidas-bacteriostáticos, pero también citotóxicos. ${ }^{4}$ En el caso propuesto, utilizamos una combinación de solución de yodo, peróxido de hidrógeno y cloruro de sodio al $9 \%$ en gran cantidad, después de aplicar los antisépticos. Esto evitó la recurrencia de los signos de infección y, luego de aplicar los antisépticos, un daño citotóxico excesivo. ${ }^{10}$

Después de un desbridamiento agresivo, es necesario cubrir el tejido óseo; para evitar el secado y la infección, se utilizó la técnica de "pie-crusting", ${ }^{6-9}$ que consiste en realizar pequeñas incisiones transdérmicas que, a través del principio de enmallado del injerto y aprovechando la elasticidad de la piel, permite lograr una cobertura completa de la herida, con baja tensión, pues las incisiones sirven como áreas de drenaje. ${ }^{7-9}$ Esta técnica ya se ha descrito, generalmente en áreas no articulares de la anatomía, pero no está muy difundida; y los resultados son muy satisfactorios.

\section{CONCLUSIONES}

En la primera consulta, es importante el desbridamiento y el lavado adecuados de la herida, para evitar también los cierres a tensión. El adecuado desbridamiento quirúrgico-mecánico, junto con la ayuda de la técnica de "piecrusting", evitó el cierre a tensión, y logró un resultado exitoso, en un solo tiempo quirúrgico, sin nuevas intervenciones y el uso de colgajos para cubrir el defecto con exposición ósea.

Conflicto de intereses: Los autores no declaran conflictos de intereses.

\section{BIBLIOGRAFÍA}

1. Kouros I, Parham G. Chronic wounds. Clin Plastic Surg 2005;32:209-22. https://doi.org/10.1016/j.cps.2004.11.011

2. Kellam J. Musculoskeletal injury. En: Smith WJ, Stahel PF (eds). Management of musculoskeletal injuries in the trauma patient. New York: Springer; 2014:198-200. https://doi.org/10.1007/978-1-4614-8551-3

3. Moran SL, Sems A. Master technique in orthopaedic surgery: soft tissue surgery. $2^{\text {nd }}$ ed. Philadelphia: Lippincott William \& Wilkins; 2016:14-8. https://doi.org/10.1016/j.jhsa.2008.09.009

4. Bishara SA, Saad AD, Shady NH. Wound cleansing, topical antiseptics and wound healing. Int Wound J 2009;6(6): 420-30. https://doi.org/10.1111/j.1742-481X.2009.00639.x

5. Kramer A, Dissemond J, Kim S, Willy C, Mayer D, Papke R, et al. Consensus on wound antisepsis: update 2018. Skin Pharmacol Physiol 2018;31:28-58. https://doi.org/10.1159/000481545

6. Singh D, Lomax A. Piecrusting to facilitate skin closure. Case report. Foot Ankle Spec 2016;9(4):367-71. https://doi.org/10.1177/1938640015620635

7. Dunbar RP, Taitsman LA, Sangeorzan BJ, Hansen ST. Technique tip: use of "pie crusting" of the dorsal skin in severe foot injury. Foot Ankle International 2007;28(7):851-3. https://doi.org/10.3113/FAI.2007.0851

8. Motley RJ, Holt PJ. The use of meshed advancement flaps in the treatment of lesions of the lower leg. J Dermatol Surg Oncol 1990;16:346-8. https://doi.org/10.1111/j.1524-4725.1990.tb00046.x

9. DiStasio AJ 2nd, Dugdale TW, Deafenbaugh MK. Multiple relaxing skin incisions in orthopaedic lower extremity trauma. J Orthop Trauma 1993;7(3):270-4. https://doi.org/10.1097/00005131-199306000-00012

10. Lu M, Hansen EN. Hydrogen peroxide wound irrigation in orthopaedic surgery. J Bone Jt Infect 2017;2(1):3-9. https://doi.org/10.7150/jbji.16690 